\title{
RESEARCH OF RFID MIDDLEWARE IN PRECISION FEEDING SYSTEM OF BREEDER SWINE
}

\author{
Weiwei Sun, Xuhong Tian *, Minjie Jiang \\ Department of Computer Science and Engineering, South China Agricultural University, \\ GuangZhou, P. R. China \\ * Corresponding author, Address: Department of Computer Science and Engineering, South \\ China Agricultural University, GuangZhou, 510642, P. R. China, Tel: +86-20-85282091, \\ Fax: +86-20-85285393, Email: tianxuhong@scau.edu.cn (TIAN Xuhong)
}

Abstract: In Precision Feeding System of Breeder Swine, RFID is used to collect some important information about the body status of individual swine, IT is banded together with the adjusting of nutrition model, so as to actualize the precision feeding based on the individual status of livestock. The special swine entity is recognized in hoggery locale and its individual information is prompted, so the corresponding breeding measures can be validated for implementing, and the individual data can be inputted immediately in locale. The RFID middleware that satisfies the requirement of enterprise is designed and actualized; RFID system is integrated seamlessly with the existing ERP system.

Keywords: breeder swine, precision feeding, RFID, middleware

\section{INTRODUCTION}

RFID (Radio Frequency Identification) is a new technology that can collect and process information quickly and correctly. It identifies the target object with radio signal automatically and obtains the unique identification and other information of a special entity (Harry, 2006). Thereby, the projects of adopting RFID tag to identify and track animal are more and more popular in recent years. The advantages of RFID tag compared with barcode ear-tag are anti-dirt, perdurable, wireless recognizing in a long distance, 
recognizing the moving object, storing and modifying certain data in the tag ( $\mathrm{Lu} \mathrm{CH}$ et al., 2006).

The research and practice of applying RFID in precision feeding of livestock has been carried out for almost twenty years internationally, and mainly focused on dairy cattle feeding. For example, RFID tags are used to recognize individual cow, determine the milking interval and reckon the milk production, determine the formula of concentrate supplement feed according to the body status of cow, determine the position of milkermachine according to the position of teats of different cow, monitor the change of milk quality and locomotion quantity of individual cow, etc (Tan XQ, 2006).

In P. R. China, RFID in agriculture are used in dairy cattle precision feeding (Xiong BH, 2005), disease resistance in dairy cattle (Liu PH, 2005), safety tracing of factory pork production ( $\mathrm{Lu} \mathrm{CH}, 2006)$, pork quality monitoring and food safety (Liu Y, 2006), etc.

RFID was researched to apply precision feeding of breeder swine in our project. Concretely, there are the following requirements or goals:

1) The feeder can acquire his intraday tasks with PDA and wireless network and recognize individual breeder swine with RFID tag, so that the feeding, mating, delivery, epidemic prevention and other tasks can be validated and implemented correctly;

2) The feeder can input individual data immediately in the hoggery with PDA and wireless network so as to update individual status of swine in management system faster and more correct. The RFID system is integrated seamlessly with existing management system and ERP (Enterprise Resource Planning) system of enterprise, the producing flow and schedule can be managed and monitored in real time. This requirement is based on the disadvantage of current mode, i.e. producing data is written on paper at first, and then inputted into computer. Not only data can't be updated on time, but also be mistakable.

3) RFID tags are used to identify the swine, feeders, containers and other important material, and the passive tag readers are installed at appropriate sites in hoggery, so that the system can ascertain and track the position of swine, feeders and so on;

4) According to the swine's individual status of physiology and health, the series of foodstuff formulas for swine are optimized in the goals of nutrition balance and lower cost, and the swine's daily nutritional requirement for routine foodstuff and micronutrient is ensured.

So far, the enterprise's existing Hoggery Management System and ERP System has been running for more than three years, thereby, the RFID middleware is needed to research that integrate RFID system and existing ERP System. 


\section{USUAL STRUCTURE OF RFID MIDDLEWARE}

RFID middleware is a kind of Message-Oriented Middleware, information is transmitted from one module to other in form of message. RFID middleware is situated between RFID reader and enterprise application (such as SCM and ERP), it is the software supporting for development and running of RFID Application (Luckham DC et al., 1998). The main roles are filter, synthesize, compute the events and data related to the tags read by readers, thus it can reduce original data transmitted from readers to enterprise applications and increase meaningful information abstracted from original data (Ding ZH, 2006) (Wang W et al., 2005). RFID middleware shields Operating System and database from the RFID hardware, such as tag, chip, antenna and reader, and it harmonizes the running of enterprise application (Astley, 2001) (Clark S et al., 2003).

Presently, the providers of RFID middleware include IBM, Microsoft, Oracle, Sybase, Sun etc (Wu M, 2007). Fig. 1 shows the structure of IBM WebSphere RFID Middleware. This middleware include two parts, Edge controller and Premises Server (Liu FG, 2006).

To/From

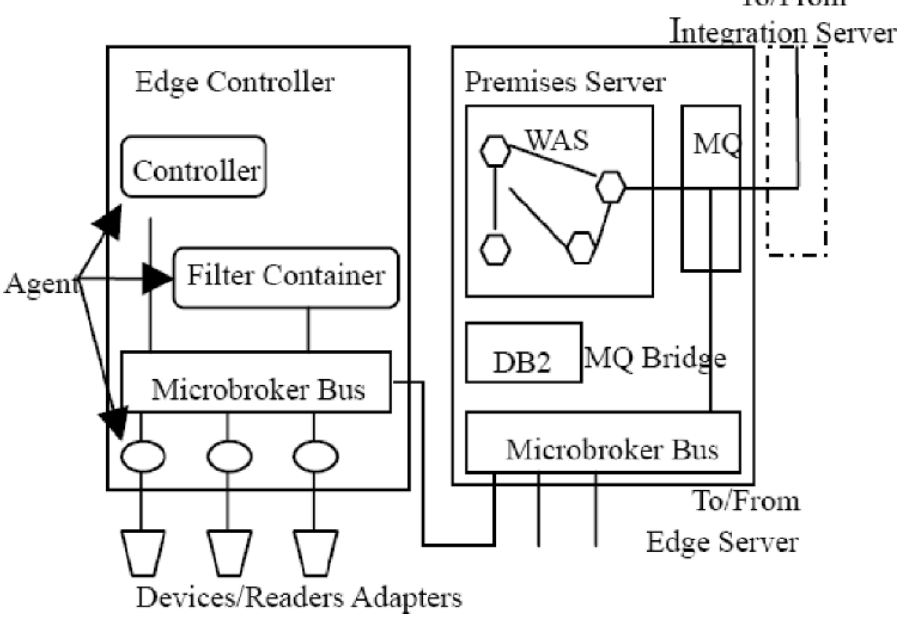

Figure 1. The structure of IBM RFID middleware

Edge controller is responsible for the communication with RFID hardware, which filters and synthesizes the data reading by reader and provides to Premises Server. Premises Server serves as the center of information collected by all RFID devices, it stores data and integrate with the management system of enterprise. Edge controller communicates with Premise Server in the mode of Publishing Topic and Subscribing Topic. The topics are published to and subscribed from Microbroker Bus. 
After readers reads tag data, Filter Container will filter tag data, and then publish to Microbroker Bus. Premises Server acquire tag data from Microbroker Bus, the Message-driven Bean in WAS will filter and clean up the data farther, then the data will be provided by MQ to enterprise application in format of XML.

Microsoft's BizTalk RFID provides an open interface based on XML and Web Services, various hardware (such as RFID, bar code, IC card) compatible with DSPI (Device Service Provider Interface) can be Plug and Play in Microsoft Windows, besides that OM/API is provided, the application program can be coded in Managed Code (such as C++.Net, VB.Net, etc.). Oracle has designed Oracle Sensor Edge Server embedded in Server 10g; it actualizes the data collecting, grouping, rule filtering, data packing and routing, organizing and managing of internal data queue before transmission (Wu M, 2007). The RFID middleware provided by Microsoft, IBM, Oracle usually are based on their own kernel production and technology, and may has more dependence and less expansibility (Ding ZH, 2006).

\section{RFID MIDDLEWARE IN PRECISION FEEDING SYSTEM OF BREEDER SWINE}

The background of project in this research is to actualize Precision Feeding System of Breeder Swine (PFSBS) in one agricultural leader enterprise of South China. This enterprise adopts "company + farmer" as producing mode, the productions include chicken, duck, swine and dairy cattle. ERP System has been actualized in the whole enterprise and Hoggery Management System in seven hoggeries of breeder swine.

In Precision Feeding System of Breeder Swine based on RFID, hardware mainly include RFID tag, reader, PDA, wireless network, hoggery server (workstation), ERP server (IBM minicomputer) etc.; software mainly include RFID middleware, application software of Precision Feeding System of Breeder Swine, ERP system, etc. The existing ERP System in enterprise adopts Oracle as Database Manage System; Sun Jsdk was selected to develop RFID middleware.

The structure of RFID middleware designed in PFSBS includes five modules, i.e. Reader Communication Interface, Event Manager, Process Manager, Mobile User Interface and Application Software Interface (Brock D, 2001) (Harry KH Chow et al., 2006). Fig. 2 shows the structure of RFID middleware and the relationship with other software and hardware.

The roles of Reader Communication Interface include configuring and monitoring and starting Passive Tag Reader, reading RFID tag data and transmitting to Event Manager. Additional functions include cooperation 


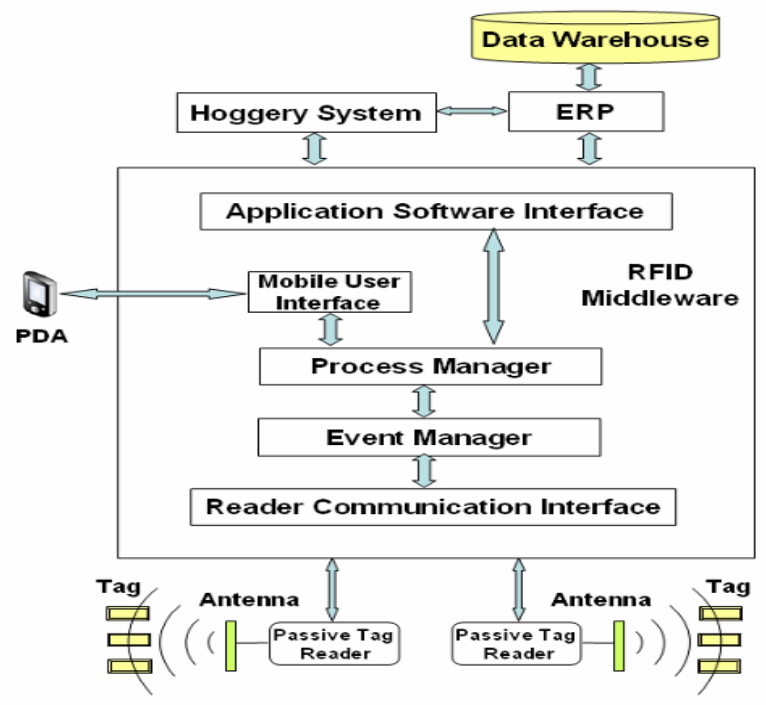

Figure 2. RFID middleware in PFSBS

between readers, anti-collision reading and writing, etc (Daniel W, 2002). The whole RFID system's usability and reliability will be depended on correct tag data provided by this module.

Event Manager has following main function (Britton C, 2001) (Ding ZH, 2006):

1) Data filtering: the wrong or redundant tag data read will be filtered, so that useful and important events will be found out, the number of event transmit to Process Manager will be reduced. Overfull data can also be buffered. Effective operations of filtering include grouping, counting, deleting redundant data, etc.

2) Data routing: different data will be transmitted to different applications according to pre-setting.

3) Event integrating: based on the actual event occurred in system, the subsets of event matching some pattern are extracted, and high-level events that accord with user's definition are produced and outputted. Such event usually has abundant semantic information, and is easy to be comprehended by applications and users.

Process Manager will ensure that processing sequence and logic of data/event is correct in terms of relevant rules. For example, reminding the feeder when he inputs an out-range data. After receiving the data inputted by feeder, Process Manager will update the processing state of the event 
accordingly, every event could have four states: Ready, Executing, Complete or Problem.

Mobile User Interface is connected with PDA via wireless network, the first role is to display the information of swine related with current tag on PDA, such as breed variety, breed state, feeding plan, immunity measure, intraday task, etc. For substituting for traditional working mode of writingon-paper, the second role is receive some producing parameters of current swine, which was inputted by the feeder in locale, such as mating date, semen ID, aborting date, delivering date, number of alive piglets, number of dead piglets, litter weight after delivery, litter weight when 21 days old, etc, all these data will be checked up by Process Manager before transmitting to Application Software Interface.

Application Software Interface connects RFID middleware with various high-level applications (such as Hoggery Management System, ERP System) or data warehouse. It transforms data into appropriate format before transmitting to high-level systems, it integrates RFID with ERP System finally.

Level by level up through these five modules, RFID tag data is transformed to match the applications' requirement, and is introduced into Hoggery Management System and ERP System. The goal of integrating RFID with existing ERP System has been achieved.

Fig. 3 and Fig. 4 are the diagrams of data flow. Fig. 3 is Tag data reading, and Fig. 4 is Tag data updating.

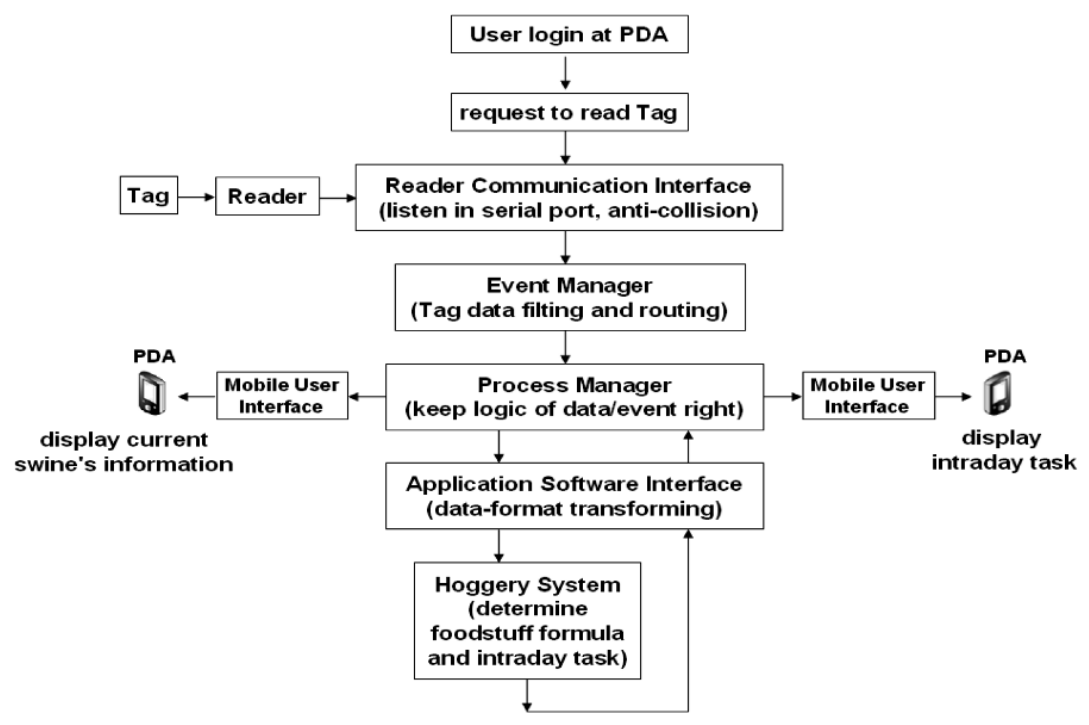

Figure 3. Data flow by Tag data reading 


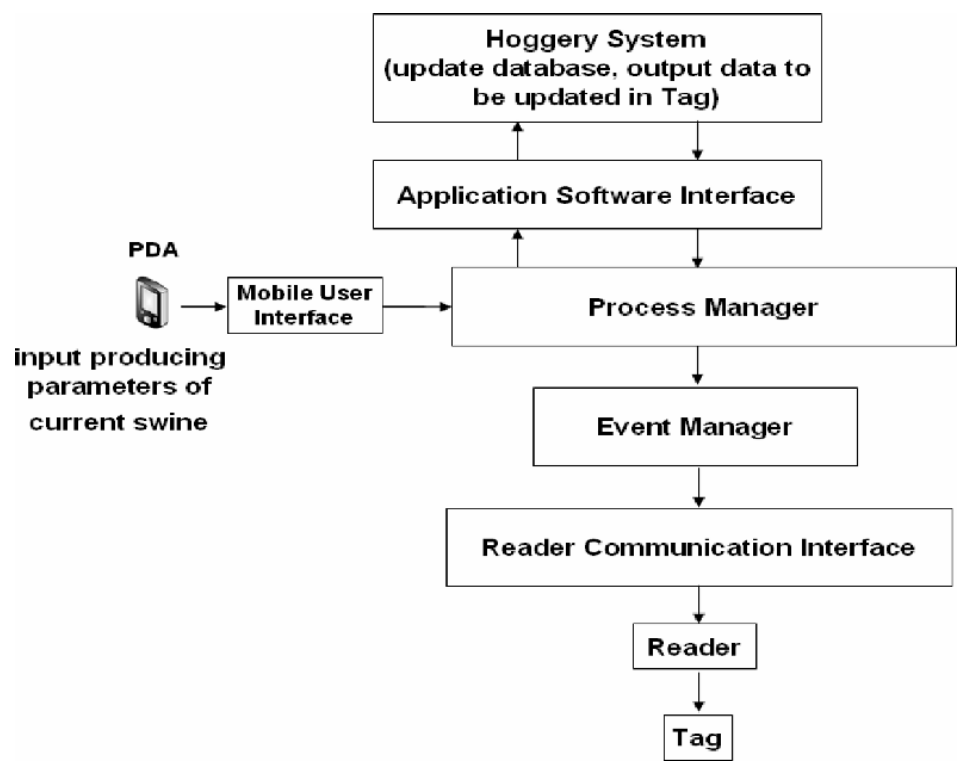

Figure 4. Data flow by Tag data updating

\section{CONCLUDING REMARKS}

RFID middleware provides the interface with RFID devices as well as the interface integrated with enterprise applications, but the research about RFID middleware is just a rising domain internationally, there is still not enough acknowledged production and comprehensive application.

In Precision Feeding System of Breeder Swine based on RFID, RFID was used to collect individual information of swine, every swine has its special tag. IT is banded together with the adjusting of nutrition model, so as to actualize the precision feeding based on the individual status of livestock. The special individual swine is identified in hoggery locale and its individual information is prompted, so the corresponding breeding measures can be validated for implementing.

For integrating RFID system with ERP System, it is necessary to study RFID middleware, so the RFID middleware is designed and actualized that accord with the requirement of enterprise. The following work will be debugging and perfecting current RFID Middleware System in practical running, and extent to other livestock feeding systems in enterprise gradually. 


\section{REFERENCES}

Astley M, Sturman. Customizable middleware for modular distributed software. Commun. ACM, 2001, 44(5): 99-107.

Britton C. Classifying Middleware. The Business Integrator Journal Winter, 2001, 27-30.

Brock D. The compact Electronic Product Code - a 64-bit representation of the Electronic Product Code. Technical Report MIT-AUTOID-WH-008, MIT Auto-ID Center, Massachusetts Institute of Technology, 2001.

Clark S, Traub K, Anarkat D. Auto-ID Savant Specification 1.0. Auto-ID Center, 2003.

Daniel W. The Reader Collision Problem. AUTO-ID CENTER White Paper. 2002, 7-12.

Ding ZH, Li JT Feng B. Survey on RFID Middleware. Computer Engineering, 2006, 32(21): 9-11.

Harry KH Chow, Choy KL, Lee WB. A dynamic logistics process knowledge-based system - An RFID multi-agent Approach. Knowledge-Based Systems, 2006, 8:1-16.

Liu FG, Jiang RL, Hu YM. RFID Middleware and Its Application in Warehouse Management. Computer Engineering, 2006, 32(13):272-273.

Liu PH, Lu CP, Zhang SH. Application of Electronic Identification in Dairy Cow Management and Disease Prevention. Animal Husbandry and Veterinary Medicine, 2005, 37(5):32-34.

Liu Y, Zeng JF, Tian LM. RFID Based Solution for Food Safety. Computer Engineering and Application, 2006, 24:201-203.

Lu CH, Xie JF, Wang LF. Completion of Digital Tracing System for the Safety of Factory Pork Production. Jiangsu Journal of Agricultural Science, 2006, 22(1):51-54.

Luckham DC, Frasca B. Complex Event Processing in Distributed Systems. Stanford University, Technical Report: CSL-TR-98-754, 1998.

Tan XQ. Advice from others may help one overcome one's shortcomings - The 8th Japan Automatic Identification Expo and sidelights of visiting Japan. China auto-identify technology, 2006, 2:32-39.

Wang W, McFarlane D, Brusey J. Timing Analysis of Real-time Networked RFID Systems. Cambridge Auto-ID Lab, Cambridge, UK, 2005.

Wu M 2007. Scan RFID Middleware productions. China auto-identify technology, 2003, $1: 66-71$.

Xiong BH, Qian P, Luo QY. Design and Realization of Solution to Precision Feeding of Dairy Cattle based on Single Body Status. Transactions of the CSAE, 2005, 21(10): $118-123$. 